\title{
SÍNDROME DO INTESTINO CURTO NA CRIANÇA - TRATAMENTO COM NUTRIÇÃO PARENTERAL DOMICILIAR
}

\author{
Uenis Tannuri \\ Trabalho realizado no Serviço de Cirurgia Pediátrica do Instituto da Criança do Hospital das \\ Clínicas da FMUSP e na clínica particular do autor, São Paulo, SP.
}

RESUMO - OвJETIVo. Em 1979 o autor utilizou, pela primeira vez no Brasil, a nutrição parenteral prolongada domiciliar em criança. 0 objetivo deste trabalho é o de apresentar a experiência da utilização deste método no tratamento de crianças com síndrome do intestino curto nos últimos 23 anos.

Métodos. Dezenove crianças com esta afecção (ressecção de mais de $75 \%$ do comprimento intestinal) foram tratadas inicialmente em hospital e a seguir no próprio domicílio. Os períodos totais de terapia nutricional variaram de quatro meses a quatro anos e meio, enquanto que as crianças permaneceram em nutrição parenteral domiciliar por períodos que variaram de uma semana a quatro anos, com mediana de oito meses. As soluções nutrientes completas, contendo aminoácidos, glicose, emulsão lipídica, eletrólitos, vitaminas e micro-elementos foram administradas através de catéteres venosos centrais do tipo Broviac ou Hickman. No domicílio, as soluções foram administradas durante o período diurno ou noturno, segundo a preferência dos familiares.

Resultados. Em todos os casos verificou-se ganho ponderal, crescimento e desenvolvimento satisfatórios, semelhantes aos obtidos durante nutrição oral. Obstruções do cateter, alterações hepáticas e infecção devida ao cateter foram as complicações mais freqüentes. Sete crianças $(37 \%)$ sobreviveram e estão fora de tratamento. Doze crianças faleceram (dez com resecção total do intestino delgado), sendo II por complicações relacionadas à nutrição parenteral (nove por infecção sistêmica e dois por embolia pulmonar maciça) e uma por complicação neurológica, dois meses após transplante duplo de intestino e fígado.

ConclusÃo. A nutrição parenteral domiciliar em crianças com síndrome do intestino curto traz indiscutíveis benefícios, permite redução do período de internação hospitalar, tornando possível a adaptação funcional do intestino remanescente e manutenção do estado nutricional com a via oral exclusiva.

UnITERMOS: Nutrição parenteral domiciliar. Pediatria. Suporte nutricional. Síndrome do intestino curto.

\section{INTRODUÇÃO}

A síndrome do intestino curto representa condição clínica muito grave, caracterizada pela deficiente absorção intestinal de nutrientes e que na criança leva ao óbito por desnutrição grave, se não adequadamente tratada. Alguns autores preferem a denominação de "síndrome do intestino encurtado", em virtude do problema ser geralmente decorrente de ressecção de extensos segmentos intestinais. As causas desta síndrome incluem afecções congênitas e adquiridas que resultam em perdas de grandes áreas de superfície de absorção intestinal, tanto in útero quanto pós-natal.

Até o final da década de 60, praticamente todas as crianças com esta síndrome faleciam por impossibilidade de suporte nutricional adequado. A partir de 1968 , com a descrição do primeiro caso de nutri-

Correspondência:

Rua Barata Ribeiro, $483-7^{\circ}$ andar CEP: 01308-000 - São Paulo - SP ção endovenosa por tempo prolongado em um recém-nascido com atresias intestinais múltiplas e conseqüente intestino curto congênito, passou-se a se obter índices progressivamente maiores de sobre vida em crianças com esta afecção e outras disfunções intestinais graves. A seguir, graças ao melhor conhecimento dos mecanismos fisiopatológicos da absorção dos nutrientes, percebeu-se a utilidade do uso clínico das dietas elementares, quimicamente definidas e desprovidas de resíduos, em pacientes com síndrome do intestino curto. Tais dietas foram primariamente formuladas para a primeira viagem do homem à Lua, em 1969.

Em 1970, foi descrita pela primeira vez a possibilidade de utilização da nutrição parenteral prolongada no domicílio do paciente. Nos primeiros casos, as soluções nutrientes eram administradas através de shunts venoarteriais, semelhantes aos utilizados para hemodiálise em pacientes com insuficiência renal crônica. Este programa terapêutico foi denominado "intestino artificial". Entre os pacientes estudados, nesta fase inicial, dois deles eram crianças portadoras de afecções intestinais crônicas graves'

Durante a década de 70, alguns pacientes submetidos à ressecção total do intestino delgado, com anastomose do duodeno com o colo ascendente, puderam sobreviver por períodos prolongados de até cinco anos graças à utilização das fístulas veno-arteriais. ${ }^{2}$ Entretanto, verificou-se que a trombose dos shunts ocorria em todos os casos em virtude da alta osmolaridade das soluções infundidas, o que tornava inviável a continuidade do tratamento. Tal complicação não ocorre em pacientes renais crônicos, em decorrência da constante hipervolemia e da reduzida adesividade plaquetária, alterações características dos urêmicos crônicos.

A partir de 1976, os autores passaram a usar, com indiscutíveis vantagens, cateteres especiais de silicone introduzidos até o átrio direito, conhecidos universalmente como cateter de Broviac ou Hickman, em virtude das 
modificações introduzidas por esses autores. Graças a estes dispositivos tornou-se possível a realização da terapêutica nutricional endovenosa por períodos de vários anos, com a possibilidade de tratamento no domicílio do paciente, o que constituiu um marco importante no tratamento de pacientes com síndrome do intestino curto ${ }^{3-5}$.

No Brasil, a nutrição parenteral domiciliar foi utilizada pela primeira vez pelo autor em 1979, em criança submetida, com 24 horas de vida, à ressecção total de intestino delgado e ceco devido à necrose irreversível causada por volvo do intestino médio. Após período inicial de nutrição endovenosa em hospital durante sete meses, a criança foi conduzida ao seu domićlio para continuidade do tratamento. Após este caso inicial, pôde-se constatar os inquestionáveis benefícios da terapia nutricional domiciliar além do maior conforto propiciado aos familiares ${ }^{6}$. Nos últimos cinco anos, o surgimento das empresas especializadas em assistência médica no domicilio do paciente ("home-cares") ampliou as perspectivas e possibilidades de realização deste método terapêutico em domicílio. A montagem de estrutura para assistência médica domiciliar tem viabilizado a alta hospitalar mais precoce, com segurança para o paciente, maior conforto aos pais e custos significantemente reduzidos.

Apesar de graves, e por vezes fatais, as complicações decorrentes da presença prolongada no cateter em veia central, infecção e tromboembolia pulmonar, ainda constituem fator limitante para a utilização da nutrição parenteral prolongada. Entretanto, este ainda é considerado o melhor método terapêutico para a manutenção das condições nutricionais em crianças com síndrome do intestino curto e outras disfunções digestivas graves.

O objetivo do presente trabalho é o de apresentar a experiência pessoal do autor e a do Serviço de Cirurgia Pediátrica do Instituto da Criança do Hospital das Clínicas da Faculdade de Medicina da USP no tratamento de crianças com síndrome do intestino curto, tratadas com nutrição parenteral domiciliar desde 1979 até o presente. Por considerar que se trata da maior experiência no Brasil e dada a ausência de relatos similares em literatura nacional, o autor julgou oportuna tal apresentação.

\section{Tabela I - Afecções primárias das crianças com síndrome do intestino curto (ressecção acima de 75\% do comprimento intestinal)}

\section{Diagnóstico}

Enterite necrosante

Volvo do intestino médio

Aganglionose cólica total + íleo terminal

Atresias intestinais múltiplas + atresia

do mesentério + intestino helicoidal

Outras

Total
Número de casos

8

5

2

3

19 casos
Pacientes: realizou-se levantamento retrospectivo dos prontuários de 19 crianças com síndrome do intestino curto tratadas inicialmente em hospital e a seguir no domicílio. Os períodos totais de terapia nutricional variaram de quatro meses a quatro anos e meio. As indicações e os números de pacientes constam na Tabela I. Dezoito crianças residiam na cidade de São Paulo e uma em Uberaba (MG). Os pais ou responsáveis aprovaram e assinaram o consentimento livre e informado da instituição hospitalar em que a criança estava internada. Tal consentimento encerra sempre a possibilidade de que o caso seja divulgado em trabalho de pesquisa clínica, desde que em caráter de anonimato.

Todas as crianças foram selecionadas para suporte nutricional por via parenteral domiciliar sempre que o comprimento do intestino ressecado correspondesse a mais de $75 \%$ do comprimento total da víscera. Das 19 crianças, dez delas haviam sido submetidas à ressecção total do intestino delgado e ceco, com anastomose do duodeno com o colo ascendente, e três apresentavam menos de $20 \mathrm{~cm}$ de intestino delgado remanescentes. Nas seis crianças restantes os comprimentos de intestino delgado variaram entre $20 \mathrm{~cm}$ e $40 \mathrm{~cm}$.

A decisão de se realizar a nutrição parenteral no domicílio da criança surgiu como necessidade natural após período de internação hospitalar, ainda com a perspectiva de terapia nutricional endovenosa por tempo muito prolongado. Após esclarecer aos pais potenciais riscos e os benefícios esperados, o procedimento só foi indicado nos casos em que houvesse plena aceitação dos familiares e ambiente domiciliar adequado.

Administração das soluções: As soluções nutrientes foram administradas através de cateteres do tipo Broviac ou Hickman .
Utilizaram-se sempre as técnicas clássicas de introdução dos cateteres por dissecção venosa ou por punção de grandes vasos, com exteriorização através de túnel subcutâneo. Em dois casos foram utilizados cateteres totalmente implantáveis ("port cath"). Todos os nutrientes foram misturados em só frasco, de um ou meio litro, de acordo com cada caso. A administração concomitante diária de emulsão lipídica permitiu que a glicose fosse fornecida em concentrações inferiores a 20\%, com menores riscos de variações bruscas de glicemia.

No período inicial, ainda durante a internação hospitalar, as soluções foram administradas continuamente durante 24 horas do dia. A seguir, iniciou-se período de adaptação, com objetivo de se administrar o mesmo volume de solução nutriente em menor número de horas. As soluções passaram a ser administradas em períodos de 12 a 15 horas, sendo que meia hora antes do término da infusão o gotejamento foi paulatinamente diminuído até a interrupção total, para se evitar risco de hipoglicemia. Em seguida, procedeu-se à heparinização do cateter (50 a 100 unidades de heparina $/ \mathrm{kg}$ de peso diluídas em $10 \mathrm{ml}$ de solução fisiológica) e oclusão da extremidade com tampa apropriada (tipo "luer-lock").

Paralelamente à fase de adaptação para infusão descontínua de nutrientes, os pais foram orientados quanto à manipulação de cateteres e soluções. Os cuidados de assepsia foram rigorosamente ensinados, lembrando que deles dependia o sucesso do tratamento e a prevenção das complicações infecciosas. A utilizaçãa de luvas estéreis pôde ser substituída por escovagem das mãos com água corrente e sabão ou iodopovidine. Este procedimento foi obrigatório antes de qualquer manipulação do cateter ou soluções. A relação do material necessário fornecida aos pais consta no Quadro I. 
Quadro I - Material fornecido aos pais por ocasião da alta hospitalar

\author{
Gaze esterilizada \\ Solução anti-séptica de iodopovidona \\ Luvas estéreis \\ Tampas do cateter (tipo "luer-lock") \\ Esparadrapo tipo "micropore" \\ Soluções nutrientes \\ Seringas \\ Agulhas hipodérmicas \\ Heparina diluída ( 10 unidades $/ \mathrm{ml})$ \\ Equipos para infusão \\ Bomba de infusão (se necessário)
}

\section{Tabela 2 - Solução padrão com a mistura de todos nutrientes em um só frasco}

\begin{tabular}{|c|c|c|}
\hline Constituinte & Quantidade & Concentração Final (por litro) \\
\hline Glicose $50 \%$ & $125 \mathrm{ml}$ & 125g de glicose \\
\hline Aminoácidos 10\% & $100 \mathrm{ml}$ & 20g de amino-ácidos \\
\hline Acetato de sódio 10\% & $20 \mathrm{ml}$ & 35 mEq de sódio \\
\hline Sulfato de magnésio 20\% & $2,5 \mathrm{ml}$ & 8 mEq de magnésio \\
\hline Fosfato biácido de potássio 25\% & $5 \mathrm{ml}$ & $\begin{array}{l}15 \text { mEq de fósforo } \\
15 \text { mEq de potássio }\end{array}$ \\
\hline Cloreto de potássio 19,1\% & $4 \mathrm{ml}$ & $\begin{array}{c}25 \text { mEq de potássio } \\
\text { (total } 40 \mathrm{mEq} / \mathrm{l} \text { ) }\end{array}$ \\
\hline Gluconato de cálcio I0\% & $10 \mathrm{ml}$ & 9 mEq de cálcio \\
\hline Ácido fólico 0,1 \% & $0,1 \mathrm{ml}$ & $0,1 \mathrm{mg}$ \\
\hline Vitamina $K_{3005 \%}$ & $3 \mathrm{ml}$ & $15 \mathrm{mg}$ \\
\hline Complexo B & I/2 amp & - \\
\hline Vitamina C 10\% & $2,5 \mathrm{ml}$ & $250 \mathrm{mg}$ \\
\hline Mistura de micro-elementos & $\mid \mathrm{ml}$ & (ver Tabela 3) \\
\hline Emulsão lípídica I0\% & $80 \mathrm{ml}$ & I6 g de lípide \\
\hline Água destilada qsp & $500 \mathrm{ml}$ & \\
\hline Osmolaridade (mOm/l) & & 1000 \\
\hline Relação N/cal & & $1 / 200$ \\
\hline
\end{tabular}

Tabela 3 - Composição da mistura de micro-elementos

\begin{tabular}{|c|c|c|}
\hline Constituinte & Quantidade (g) & Concentração $(\mathrm{mcg} / \mathrm{ml})$ \\
\hline $\mathrm{ZnSO}_{4} \cdot 7 \mathrm{H}_{2} \mathrm{O}$ & 1,9 & zinco- 400 \\
\hline $\mathrm{CuSO}_{4}^{4} . \mathrm{H}_{2}^{2} \mathrm{O}$ & 0,9 & cobre-200 \\
\hline $\mathrm{NaF}$ & 0,22 & fluor-10 \\
\hline & 0,069 & iodo-59 \\
\hline $\mathrm{MnSO}_{4} \cdot \mathrm{H}_{2} \mathrm{O}$ & 0,62 & manganês-200 \\
\hline
\end{tabular}

Após período de treinamento, a criança foi transferida para casa e, nos primeiros dias, houve o auxilio de enfermeira ou auxiliar de enfermagem especializada. Em dois casos, o tratamento foi efetuado por empresa de atendimento domiciliar ("home-care"). No domicílio, as soluções foram administradas durante o período diurno ou noturno, segundo a preferência dos familiares. A vantagem do primei- ro foi a maior segurança, o que tornou prescindível a utilização de bombas de infusão. Se a administração fosse feita durante a noite, a criança poderia ter atividade normal durante 0 dia, porém foi indispensável a utilização de bomba de infusão com sistema de alarme, para o caso de entrada de ar no sistema de equipos.

As crianças com peso até $10 \mathrm{~kg}$ receberam as soluções nutrientes em volume diário de
$130 \mathrm{ml} / \mathrm{kg}$ peso, durante o período de tempo determinado. Crianças maiores recebiam volumes de solução que fossem suficientes para adequado ganho ponderal. Meia hora antes de interromper a administração da solução nutriente, a velocidade de infusão era reduzida paulatinamente e, em seguida, o cateter era heparinizado, semelhante ao esquema utilizado durante o período de internação hospitalar.

As soluções, preparadas em farmácias especializadas de manipulação (fórmulas especificadas nas Tabelas 2 e 3), em condições técnicas de rigorosa assepsia, eram fornecidas aos pais uma ou duas vezes por semana. No domicílio, foram conservadas em geladeira comum, com temperatura em torno de $4^{\circ} \mathrm{C}$. Mesmo as soluções completas, contendo inclusive lípides, puderam ser preparadas e estocadas em geladeira, por períodos de até quatro semanas. As soluções não foram manipuladas no domićílio, com o objetivo de eliminar a possibilidade de erros técnicos ou de contaminação.

As vitaminas lipossolúveis $A$ (retinol), D (calciferol) e $B_{12}$ (hidroxi ou cianocobalamina), ausentes na solução padrão, foram fornecidas a cada mês por via intramuscular nas doses de I 400 e 400 unidades e $100 \mu \mathrm{g}$ respectivamente. A biotina (vitamina $\mathrm{H}_{\text {ou }} \mathrm{B}_{7}$ ) foi fornecida a cada dois ou três meses por via oral, sob forma de solução ou em misturas de multivitaminas formuladas especificamente para uso endovenoso.

O controle clínico, no início, foi feito a cada dois dias e, a seguir, semanalmente ou mesmo de acordo com as necessidades de cada caso. Os volumes de solução nutriente foram aumentados na proporção em que ocorria ganho ponderal. Os exames laboratoriais rotineiros de controle foram baseados nas características clínicas do paciente: hemograma completo, dosagem de eletrólitos, cálcio, fósforo, magnésio e albumina no plasma, se necessário. A avaliação da função hepática foi efetuada sempre que surgia hepatomegalia ao exame físico ou icterícia.

Nos seis casos iniciais da série, realizou-se gastrostomia para facilitar a descompressão do tubo digestivo nas fases iniciais de pós-operatório e, a seguir, para administração de dietas. Sempre que possível a via digestiva oi utilizada, com o fornecimento de dietas quimicamente definidas ou mesmo alimentos naturais apropriados, mesmo nas crianças com ressecção total de intestino delgado. 


\section{Resultados}

Os pacientes permaneceram em nutrição parenteral domiciliar por períodos que variaram de uma semana a quatro anos, com mediana de oito meses. Houve boa aceitação dos familiares e aderência a todos os procedimentos técnicos necessários à realização do método terapêutico em 18 casos. Em uma criança submetida à nutrição parenteral durante 18 meses, o tratamento foi realizado no domićlío por apenas uma semana, devido à falta de condições ambientais e familiares para a execução do método.

Em todos os casos verificou-se ganho ponderal, crescimento e desenvolvimento satisfatórios, semelhantes aos obtidos durante nutrição oral. Foi particularmente importante e notável a observação de que as crianças submetidas à nutrição endovenosa no primeiro ano de vida, desde o período neonatal, apresentaram desenvolvimento neuro-psicomotor próximo ao normal, com a capacidade de sentar em torno do $7^{\circ}$ mês de vida e deambular em torno do $13^{\circ}$ mês de vida (Figura I).

Complicações técnicas: Obstruções do cateter por coágulos constituíram o problema mais freqüente, observado pelo menos por duas a seis vezes em cada caso. Diante da impossibilidade de se obter a desobstrução da luz do cateter, este era trocado por outro, aproveitando-se a mesma veia.

Infecções: Em ordem de freqüência, a segunda complicação mais observada foi infecção decorrente da presença do cateter. Em todos os casos observaram-se quadros de processo infeccioso, que variaram entre dois e quatro episódios por criança. As infecções localizadas se manifestaram pela presença de secreção purulenta no túnel subcutâneo do cateter ou apenas no local de entrada na pele, enquanto que as infecções sistêmicas, pela presença de febre, comprometimento do estado geral, hemograma com leucocitose com ou sem a identificação do micro-organismo na hemocultura. Quando presentes em exames de cultura do sangue, os micro-organismos mais freqüentemente identificados foram Staphylococcus aureus, Staphylococcus epidermidis e Candida albicans. A primeira opção para o tratamento dos episódios de infecção sistêmica foi sempre a administração endovenosa de antibióticos específicos através do próprio cateter, ou de anfotericina B, nos casos de infecção fúngica. Diante da falta de resposta
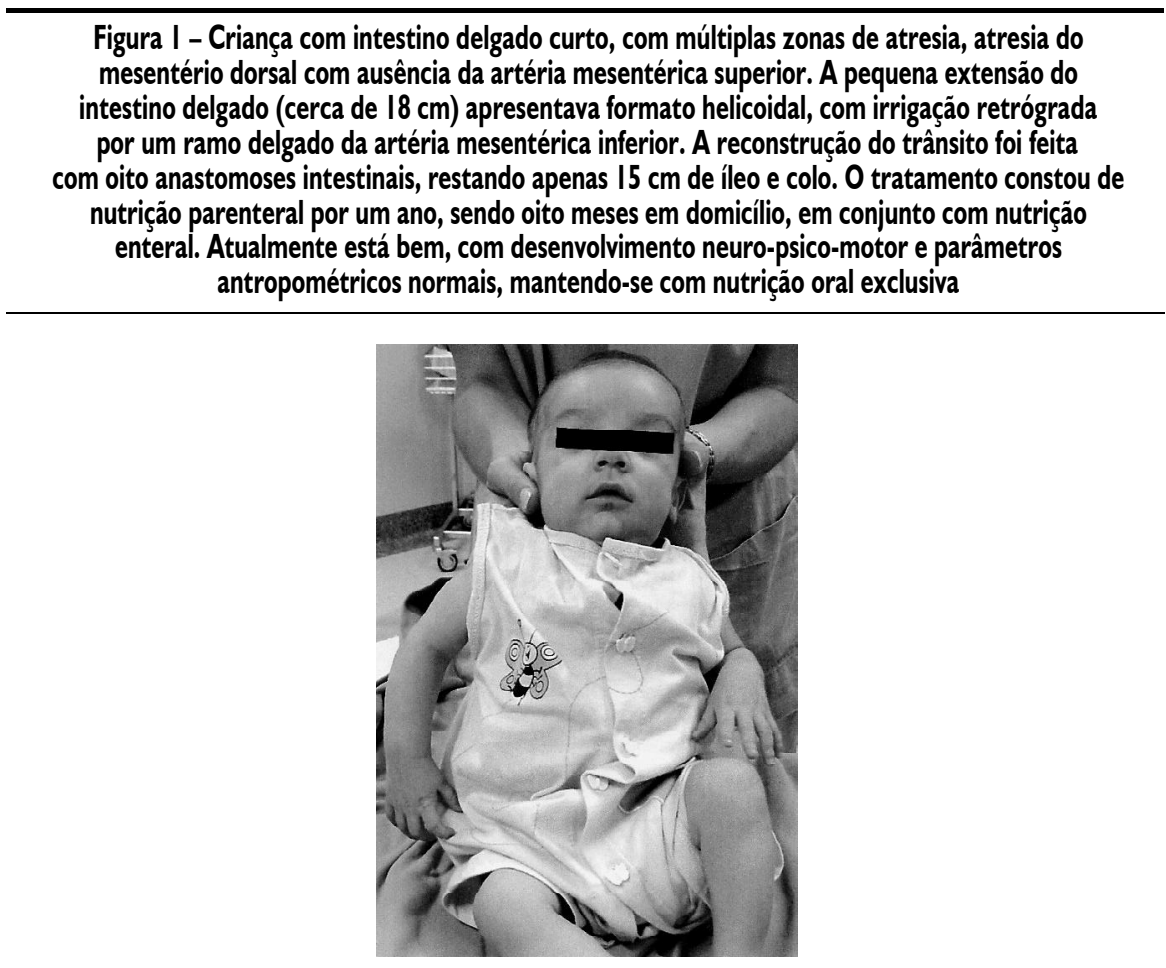

favorável, representada pala permanência de febre, o cateter era retirado e a nutrição parenteral interrompida ou substituída por esquema de nutrição através de veias periféricas. Após o desaparecimento da febre, a criança era novamente levada ao centro cirúrgico para colocação de novo cateter.

Complicações metabólicas: Todas as crianças apresentaram algum tipo de alteração hépato-celular durante o tratamento, representada por hepatomegalia ao exame clínico, icterícia, aumento dos níveis séricos de transaminases, gamaglutamil transpe ptidase e bilirrubinas, sendo que uma criança apresentou falência hepática aguda. No entanto, na maioria das vezes, não foi possível determinar se estas alterações eram dependentes da nutrição parenteral ou de algum surto de infecção sistêmica ou no local do cateter. A principal alteração nos níveis séricos dos eletrólitos foi desidratação hiponatrêmica com ou sem hipocalemia, decorrente de episódios de diarréia. Outras alterações séricas de eletrólitos foram pouco freqüentes, desde que as necessidades diárias foram adequadamente fornecidas e as crianças recebiam nutrição oral ou enteral concomitante. Hipoglicemia devido à interrupção do fluxo de solução nutriente não foi observada.
Em três crianças, após quatro meses de suporte nutricional exclusivo, verificou-se o aparecimento de lesões cutâneas e na comissura labial que regrediram após a administração empírica de biotina, o que nos fez supor o diagnóstico de deficiência específica desta vitamina.

Durante todo tratamento domiciliar as crianças receberam dietas por via digestiva. A avaliação clínica demonstrou, de modo geral, que não houve vantagens em utilizar dietas elementares ou semi-elementares quanto ao número diário de evacuações, aspecto e volume das fezes, e finalmente quanto ao ganho ponderal. Assim, preferiu-se, geralmente, o fornecimento de alimentos naturais, com pouco resíduo, feitos de carne de peito de frango com batata, arroz ou macarrão.

Resultado final: Sete crianças (37\%) sobreviveram e estão fora de tratamento, com nutrição oral e livres de terapia endovenosa. Todas as crianças submetidas à ressecção total do intestino delgado faleceram. As complicações relacionadas com a nutrição parenteral foram responsáveis por doze óbitos: nove por infecção sistêmica e dois por embolia pulmonar maciça. Uma criança faleceu por complicação neurológica não esclarecida, dois meses após transplante duplo de 
intestino e fígado. Tratava-se de lactente de seis meses de idade com enterite necrosante maciça com necrose concomitante da metade inferior do esôfago. Após o restabe lecimento do trânsito intestinal, através de anastomose do duodeno com o colo ascendente, a continuidade do trânsito esofágico foi restabelecida por esofagogastroplastia. Após seis meses de permanência hospitalar, a criança permaneceu em nutrição parenteral domiciliar por apenas uma semana, devido à falta de condições do ambiente familiar, retornando ao hospital. Após um ano e meio, apresentou falência hepática pela nutrição parenteral, tendo sido submetida a transplante duplo de intestino e fígado, falecendo dois meses após.

\section{Discussão}

A síndrome do intestino curto foi a primeira indicação para nutrição parenteral prolongada em seres humanos e, no Brasil, o primeiro motivo para que o método fosse realizado no domićlilo do paciente. Nos dias de hoje, continua sendo a principal indicação na criança, seguida da síndrome da pseudo-obstrução intestinal $\left.\right|^{7}$ e outras afecções, citadas na literatura, porém pouco freqüentes em nosso meio, doença de Crohn, diarréia crônica de causas indeterminadas e enteropatia por deficiência imunológica ${ }^{8}$.

Até meados da década passada, em crianças com insuficiências intestinais graves sem possibilidade de adaptação funcional, a nutrição parenteral prolongada era a única opção terapêutica para manutenção da vida. Nos últimos anos, tem surgido novo método terapêutico representado pelo transplante de intestino delgado, isolado ou em conjunto com o fígado, em casos de falência hepática pela nutrição parenteral prolongada?. Entretanto, este recurso ainda não está disponível em nosso meio, é extremamente dispendioso com custo estimado entre 500.000 e I milhão de dólares. Assim, em um caso foi possível a alocação de recursos por parte da família para que se realizasse o transplante na Universidade de Miami (EUA). Dois meses após o procedimento, a criança apresentou quadro neurológico súbito representado por crises convulsivas sub-entrantes seguida de parada cardíaca irreversível.

O transplante de intestino delgado, com sobrevida nos dias de hoje em torno de
$50 \%$, deve ser reservado para aqueles casos em que não existe qualquer perspectiva de retorno à nutrição oral exclusiva, ou seja, quando o duodeno é anastomosado ao colo ascendente. Pequenos segmentos remanescentes de intestino delgado, com extensão de $15 \mathrm{~cm}$ ou $20 \mathrm{~cm}$, são passíveis de adaptação em longo prazo, como observamos em três casos.

Nas crianças com alguma extensão de intestino delgado remanescente, verifica-se que ocorre significativa dilatação deste intestino, como um natural fenômeno de adaptação funcional. Nos últimos anos, têm sido relatadas técnicas cirúrgicas para alongar este segmento intestinal remanescente ${ }^{\mid 0,11}$. No entanto, a prática mostra que estes procedimentos são complicados e ineficazes, pois não promovem aumento da área de superfície de absorção de nutrientes.

Tratamento domiciliar: A possibilidade de realizar a nutrição parenteral domiciliar permite maior conforto não somente à criança, mas traz também comodidade aos pais e familiares. Além deste fato, deve-se levar em conta as indiscutíveis vantagens econômicas, já que são abolidos os custos da internação hospitalar. Assim, a nutrição parenteral domiciliar, realizada pelos pais, com auxílio de profissionais de enfermagem, ou mesmo por serviços de "home-care", tem sido de grande interesse dos planos de assistência médica e seguros de saúde.

Desde o primeiro caso que tratamos, em 1979, e em todos os outros seguintes, verificou-se que não houve dificuldade do ponto de vista médico ou de assistência de enfermagem para o tratamento domiciliar. Os maiores obstáculos foram o nível sociocultural dos familiares para a compreensão do problema, a vontade e determinação para a continuidade do tratamento em domićlio e, finalmente, a existência de condições propícias no ambiente domiciliar. Em apenas um caso, apesar de adequadas condições sociais, econômicas e culturais dos pais, a coexistência de quatro outros irmãos inviabilizou a continuidade do tratamento no domicílio. Desta forma, toda criança internada em hospital, com perspectiva de tratamento nutricional endovenoso por tempo prolongado, deve ser considerada a possibilidade de transferência direta para seu domicílio, após o período inicial de estabilização das condições clínicas.

\section{Capacidade de aprendizado dos pais e aceitação do problema: Geralmente, o} convívio diário dos pais com a criança, durante o longo período de internação hospitalar, permite a assimilação inicial de vários conhecimentos técnicos sobre a nutrição parenteral. A seguir, diante da perspectiva de alta hospitalar, os pais passam a captar, a partir da equipe médica, das enfermeiras e auxiliares de enfermagem todos os outros detalhes necessários: técnicas de assepsia e de lavagem das mãos, estocagem e manipulação das soluções nutrientes, conhecimento e familiarização com o cateter venoso, técnica de curativos, heparinização do cateter, manipulação da bomba de infusão e dos equipos, medidas da glicemia e ou glicosúria, resolução de eventuais problemas e o que fazer em situações de emergência. A avaliação da capacidade de aprendizado deve ser feita durante os dois ou três dias que antecederem a alta hospitalar, em que todo o tratamento deve ser feito pelos pais sob supervisão da enfermagem.

Fornecimento das soluções: Nos casos iniciais, entre 1979 e 1985, foram utilizadas soluções nutrientes contendo glicose a $20 \%$, sem emulsão lipídica. A partir de trabalhos realizados in vivo e in vitro sobre estabilidade das emulsões lipídicas misturadas com soluções nutrientes, passou-se a utilizar as misturas em um só frasco (sistema "all-in-one" ou "três em um").

Diante das dúvidas de que as misturas completas de soluções nutrientes provocassem a perda da estabilidade das emulsões gordurosas, foi demonstrado inicialmente que a administração de tais misturas a animais de experimentação, em fase de crescimento, nada acarretou. Da mesma forma, o exame anatomopatológico dos pulmões destes animais também não demonstrou qualquer alteração ${ }^{12}$. Estudos posteriores in vitro, com microscopia eletrônica e com contador eletrônico de partículas, mostraram que, quando se utilizam concentrações de glicose até 25\%, as misturas com emulsões lipídicas são estáveis por períodos de até quatro semanas ${ }^{13-16}$. As membranas e os diâmetros das partículas lipídicas (liposomas) não se alteram e não ocorre confluência ou agregação dessas partículas, em decorrência da estabilidade do $\mathrm{pH}$, entre 5,8 e 6,0, conferida pela presença dos aminoácidos que, por serem ácidos fracos, funcionam como sistema tampão ${ }^{14}$. 
As soluções nutrientes completas, feitas em farmácias especializadas de manipulação, puderam ser fornecidas aos pais a cada duas semanas e estocadas em geladeira a $4^{\circ} \mathrm{C}$.

Acesso vascular - complicações: Em todos os casos foram utilizados cateteres centrais introduzidos através de dissecções de veias periféricas ou punção de veia subclávia, jugular interna ou femoral. Foram preferidos os cateteres de Broviac ou Hickman por reunirem indiscutíveis vantagens em relação a outros similares. Em apenas dois casos, no início da série, foram utilizados cateteres simples de silicone, pois na época eram os únicos disponíveis no mercado. Mais recentemente, com o advento dos cateteres totalmente implantáveis, pôde-se também utilizar este tipo de dispositivo em duas crianças, com bons resultados. Entretanto, a prática demonstrou que estes últimos apresentam os inconvenientes de requerer a punção percutânea para serem utilizados e com certa freqüência não permitem a colheita de amostras de sangue.

O cateter venoso central foi o principal responsável pelas complicações técnicas da nutrição parenteral domiciliar: obstruções da luz e infecção (localizada ao nível do túnel subcutâneo ou infecção sistêmica).

Logo após a colocação do cateter na veia, podem se formar agregados de fibrina e plaquetas em torno do mesmo, por se tratar de corpo estranho dentro da circulação sangüínea. Esse fenômeno depende principalmente da qualidade do material de que é fabricado o catéter. A extremidade distal é o principal local de formação do agregado e, se for de grandes proporções, pode até ocluir o cateter ou servir de local de acúmulo de bactérias ou fungos. No entanto, a obstrução do cateter por coágulos de sangue ocorre freqüentemente em conseqüência de interrupções inadvertidas do fluxo da solução nutriente ou heparinização inadequada. Observa-se dificuldade do fluxo de soluções através do cateter e ausência de refluxo de sangue durante aspiração. Para o tratamento recomenda-se preencher a luz do cateter com heparina e oclusão do mesmo. Após 12 a 24 horas, período em que pode haver retração do coágulo, tenta-se a aspiração do mesmo. Se após duas ou três tentativas de desobs trução não se obtiver sucesso, indica-se a injeção de agentes trombolíticos como a uroquinase ou estreptoquinase, recurso este nunca utilizado na presente série4.
Outra causa de oclusão do cateter é a formação de eventuais precipitados no frasco contendo a solução nutriente. Os elementos mais comumente responsáveis por esse problema são o cálcio e o fosfato. Sabe-se que pequenas elevações do pH da solução podem causar a precipitação do sal de cálcio ao formar complexos insolúveis com o ânion fosfato, contido na solução sob forma de fosfato biácido de potássio ${ }^{17,18}$. Em geral, não se consegue a desobstrução do cateter, sendo recomendável a troca cirúrgica do mesmo, aproveitando-se a mesma veia.

Diante das situações de obstrução do cateter ou infecção, deve-se tentar a qualquer custo evitar a remoção do cateter, tendo-se em mente que a falta de via de acesso vascular constituirá o fator limitante para a nutrição parenteral. Desta forma, especial ênfase deve ser dada aos pais sobre os cuidados de manutenção do cateter, heparinização, curativos e manipulação com técnica asséptica.

Até o presente, não há método para a prevenção das infecções veiculadas por cateter venoso central, além dos classicamente conhecidos: manipulação com rigorosa assepsia e limpeza do local de entrada na pele com solução anti-séptica. Quanto aos fatores de risco, há unanimidade na literatura que as crianças com síndrome do intestino curto apresentam maior predisposição às infecções, através da translocação bacteriana a partir da luz intestinal ${ }^{19-23}$

$\mathrm{Na}$ presente casuística, chama a atenção a grande incidência de complicações hepáticas. Tais problemas têm sido relatados com freqüência de $15 \%$ a $65 \%$ dos pacientes em nutrição parenteral domiciliar. ${ }^{24,25}$ Há evidências de que pacientes com ausência total de intestino delgado e conseqüente anastomose direta do duodeno com o colo, este último com grande flora bacteriana, são mais propensos a desenvolver tal complicação ${ }^{26}$.

A etiologia das alterações hepáticas durante a nutrição parenteral ainda não está completamente elucidada. Verifica-se, na prática, que as lesões hepáticas de recém-nascidos e especialmente prematuros ocorrem com freqüência e gravidade significativamente maiores do que em lactentes, pré-escolares ou adultos. Resulta desta observação clínica a natural conclusão de que a imaturidade hepática é fator importante na patogenia das lesões deste órgão durante a nutrição parenteral. Outro fato, conforme o que foi observado na presente casuística, é a dificuldade de se estabelecer o diagnóstico diferencial entre lesão hepática decorrente pela nutrição parenteral e colestase em virtude de processo infeccioso. Finalmente, é clássico o conhecimento de que translocação de bactérias do colo e passagem de endotoxinas para o sistema porta, fenômenos que ocorrem em maior incidência em crianças com intestino curto, constituem fatores causais para o desenvolvimento de lesões hepáticas ${ }^{27}$.

O desequilíbrio dos níveis de aminoácidos plasmáticos pode também ter papel nos mecanismos de lesão hépato-celular. A taurina, aminoácido essencial para recém-nascidos, está ausente nas soluções de aminoácidos cristalinos utilizados no Brasil. Este aminoácido é fundamental para a conjugação do ácido cólico em ácido taurocólico e sua deficiência pode acarretar alterações no fluxo biliar e colestase. Assim, postula-se que soluções de aminoácidos que atendem especificamente as necessidades de recém-nascidos promovem índices menores de complicações hepáticas, em decorrência da manutenção de um perfil de aminograma plasmático mais próximo daquele obtido com nutrição ora| ${ }^{28,29}$.

Em duas publicações recentes, foi estabelecido um protocolo para reduzir a incidência de lesões hepáticas em crianças com intestino curto durante nutrição parenteral domiciliar, dando especial ênfase à prevenção da dismotilidade da alça intestinal remanescente e translocação bacteriana. Os itens deste protocolo incluíram: I) utilização de drogas para correção da dismotilidade intestinal (Cisaprida); 2) prevenção de translocação de bactérias anaeróbias através do uso enteral de metronidazol e aminoglicosídeos; 3) administração enteral de dietas não-elementares contendo glutamina para manter o trofismo do enterócito; 4) infusão de soluções parenterais nutrientes contendo taurina; 5) vigilância rigorosa dos processos infecciosos e 6) interrupção da nutrição parenteral em determinados períodos do dia ("nutriçãao paren teral cíclica") ${ }^{30,31}$.

Finalmente, estudos recentes de biologia molecular e formação intra-hepática de bile trouxeram algumas explicações sobre a possível etiologia das alterações hepáticas durante nutrição parenteral. $\mathrm{O}$ gene $\mathrm{mdr} 2$ ("multidrug resistent"), principal responsável 
pela secreção de fosfolípides na bile, apresenta acentuado decréscimo em sua expressão durante períodos de nutrição parenteral superiores a sete dias, em modelos animais de experimentação. Este fato sugere que a perda da expressão do gene mdr2 em prematuros submetidos à nutrição parenteral possa contribuir para o desenvolvimento de colestase e lesão hépato-celular ${ }^{27}$.

Dietas enterais: Aspecto interessante a ser discutido na presente série refere-se à resposta de crianças com síndrome do intestino curto às dietas enterais. São indiscutíveis as vantagens da administração concomitante de nutrientes por via enteral para o trofismo e adaptação do intestino remanescente, principalmente as dietas com alto teor em glutamina, conforme já frisado. Embora seja abundante o número de trabalhos na literatura médica mostrando as vantagens das dietas previamente digeridas, elementares ou semi-elementares, pudemos verificar sempre que tais dietas não promoviam qualquer melhora na consistência das fezes e no número aumentado de evacuações. Assim, nossa opção baseou-se em alimentos naturais, com baixo teor em fibras, com proteína de fácil digestão: sopa de peito de frango, com batata ou macarrão e óleo de milho. Um estudo prospectivo recente, utilizando crianças com diarréia persistente e desnutrição grave, concorda com nossa observação clínica. Demonstrou-se significativa vantagem da sopa de frango em comparação com dieta elementar e leite de soja, particularmente quanto ao melhor balanço nitrogenado ${ }^{32}$. Finalmente, outras vantagens inquestionáveis dos alimentos naturais sobre as dietas elementares são melhor sabor e custo significativamente mais reduzido.

Mortalidade: Na presente série, verificouse sobrevida final de $37 \%$ dos casos, um pouco abaixo de outras séries referidas na literatura ${ }^{7}$. Acreditamos que o principal motivo deste alto índice de mortalidade decorra da grande número de casos sem perspectiva de adaptação do intestino remanescente, com anastomose do duodeno com o colo ascendente ou transverso. Em tais situações, a única opção consiste em transplante do intestino delgado, recurso não disponível no Brasil, conforme frisado anteriormente. A manutenção de cateter venoso central por tempo muito prolongado, superior a um ou dois anos, cria condições favoráveis para a ocorrência de infecção sistêmica grave ou tromboembolismo pulmonar maciço, este último sendo responsável por dois óbitos.

Em conclusão, a nutrição parenteral domiciliar representa boa opção terapêutica para crianças portadoras de síndrome do intestino curto com perspectiva de longo tempo de terapia endovenosa. A possibilidade de tratamento domiciliar e a alta hospitalar trazem benefícios à criança e aos familiares, e em alguns casos consegue-se a adaptação funcional do intestino remanescente, a ponto de ser possível interrupção da nutrição endovenosa e nutrição oral exclusiva.

\section{Conflito de interesse: não há.}

\section{SUMMARY}

\section{SHORT BOWEL SYNDROME IN CHILDREN - TREATMENT WITH HOME PARENTERAL NUTRITION}

BACKGROUND. In 1979 the author first utilized the method of home parenteral nutrition in a child in Brazil. The purpose of this paper is to present the experience, during the last 23 years, of treatment of children with short bowel utilizing home parenteral nutrition.

METHODS. Nineteen children with short bowel syndrome (resection of more than $75 \%$ of total intestinal length) were initially treated in the hospital and then nutrition therapy was continued at home. Total duration of nutrition therapy ranged from 4 months to 4 years and a half, while periods of home nutrition therapy ranged from I week to 4 years (median 8 months). Complete nutrition mixtures containing amino acids, glucose, lipid emulsion, electrolytes, vitamins and micro-elements were administered through Broviac or Hickman central venous catheters. Solutions were infused during the day or the night according to preference of the parents.

RESULTS. In all cases weight gain, growth and development similar to normal children under oral nutrition were verified. Catheter occlusion, liver dysfunction and sepsis related to the catheter were the most frequent complications. Seven children (37\%) are alive and treatment free. Twelve children died (ten of them with resection of the entire small bowel and cecum), I I due to parenteral nutrition complications (nine due to catheter sepsis and two due to massive pulmonary embolization) and one child died with neurological complications after a combined liver and small bowel transplantation.
CONCLUSION. Home parenteral nutrition is sometimes the only therapeutic choice for children with short bowel syndrome and promotes a maximal level of comfort to the patient and to the parents. Furthermore it reduces the period of hospitalization, while adaptation of the remaining small bowel occurs with maintenance of the nutritional status by oral route. [Rev Assoc Med Bras 2004; 50(3): 330-7]

KEY wORDS: Home parenteral nutrition. Child. Parenteral nutrition. Short bowel syndrome.

\section{REFERÊNCIAS}

I. Scribner BH, Cole JJ, Christopher TG, Vizzo JE, Atkins RC, Blagg CR. Long-term total parenteral nutrition. The concept of an artificial gut. JAMA 1970; 21 2:457-62.

2. Heizer WD, Orringer EP. Parenteral nutrition at home for 5 years via arteriovenous fistulae. Supplemental intravenous feedings for a patient with severe short bowel syndrome. Gastroenterology 1977; 72:527-32.

3. Riella MC, Scribner BH. Five year's experience with a right atrial catheter for prolonged parenteral nutrition at home. Surg Gynecol Obstet 1976; 143:205-12.

4. Moukarzel AA, Haddad I, Ament ME. 230 patient years of experience with home longterm parenteral nutrition in childhood: natural history and life of central venous catheters. J Pediatr Surg 1994; 29: 1323-8.

5. Ament ME. Home parenteral nutrition in infants and children. In Rombeau JL, Caldwel MD: Parenteral nutrition. Philadelphia: WB Saunders; 1986. p.731-45.

6. Brito IA, Mathias AL, Tannuri U, Bastos JC. Sobrevida prolongada e nutrição parenteral domiciliar em criança submetida à ressecção total do intestino delgado e ceco. J Pediatr (Rio de J) 1982; 52:223-8.

7. Puntis JW. Home parenteral nutrition. Arch Dis Child 1995; 72:186-90.

8. Bisset WM, Stapleford P, Long S, Chamberlain A, Sokel B, Milla PJ. Home parenteral nutrition in chronic intestinal failure. Arch Dis Child 1992; 67:109-14.

9. Iyer K, Kaufman S, Sudan D, Horslen S, Shaw B, Fox I, et al. Long-term results of intestinal transplantation for pseudo-obstruction in children. J Pediatr Surg 2001; 36:174-7.

10. Kim HB, Fauza D, Garza J, Oh TH, Nurko S, Jaksic T, et al. Serial transverse enteroplasty (STEP): A novel bowel lengthening procedure. J Pediatr Surg 2003; 38:425-9.

II. Bianchi A. Intestinal loop lengthening: a technique for increasing small intestinal length. J Pediatr Surg 1980; I 5: | 45-51.

12. Tannuri U, Chapchap P, Sesso A, Maksoud JG. Must fat emulsion and parenteral nutrition solutions be given through separate circuits? J Pediatr Surg 1987; 22:132-6. 
13. Tannuri U, Sesso A, Coelho MCM, Maksoud JG. Long term stability of lipid emulsion with parenteral nutrition solution. Nutrition 1992; 8:98-102.

14. Black CE, Popovich NG. Stability of intravenous fat emulsion. Arch Surg 1980; | 15:89|.

15. Pamperl H, Kleinberger G. Stability of intravenous fat emulsion. Arch Surg 1982; 1 17:859.

16. Poole RL. Problems with preparation of parenteral nutrition solutions. In Kerner JA Jr. Manual of pediatric parenteral nutrition. New York: John Wiley \& Sons; 1984. p. 178.

17. Kfouri Filho, M. Compatibilidade de soluções para nutrição parenteral. In Telles Jr M, Tannuri $\cup$. Suporte nutricional em pediatria. São Paulo: Atheneu; 1994. p. 143.

18. Sigalet DL. Short bowel syndrome in infants and children: an overview. Semin Pediatr Surg 2001; 10:49-55.

19. Terra RM, Plopper C, Waitzberg DL, Cukier S, Santoro S, Martins JR, et al. Remaining small bowel length: association with catheter sepsis in patients receiving home total parenteral nutrition: evidence of bacterial translocation. World J Surg 2000; |537-4|.

20. De Agustin JC, Vazquez JJ, Rodriguez-Arnao D, Canals MJ, Soler J, Alvarez E, et al. Severe short-bowel syndrome in children. Clinical experience. Eur J Pediatr Surg 1999; 9:236-4I.

21. Smith CE, Curtas S, Kleinbeck SV, Werkowitch M, Mosier M, Seidner DL, et al. Clinical trial of interactive and videotaped educational interventions reduce infection, reactive depression, and rehospitalizations for sepsis in patients on home parenteral nutrition. J Parenter Enteral Nutr 2003; 27: I37-45.

22. Grant J. Recognition, prevention, and treatment of home total parenteral nutrition central venous access complications. J Parenter Enteral Nutr. 2002; 26:S2I-8.

23. Vargas J, Ament ME, Berquist WE. Long term home parenteral nutrition in pediatrics: ten years experience in 102 patients. J Pediatr Gastroenterol Nutr 1987; 6:24-32.

24. Cavicchi M, Beau P, Crenn P, Degott C, Messing B. Prevalence of liver disease and contributing factors in patients receiving home parenteral nutrition for permanent intestinal failure. Ann Intern Med 2000; 132:525-32.

25. Messing B, Crifenn P, Beau P, Boutron-Ruault MC, Rambaud JC, et al. Long-term survival and parenteral nutrition dependence in short bowel syndrome. Gastroenterology 2000; 1 17; 1043-8.

26. Teitelbaum DH, Tracy T. Parenteral nutritionassociated cholestasis. Sem Pediatr Surg 200 I; 10:72-76.
27. Moss RL, Das JB, Ansari G, Raffensperger JG. Total parenteral nutrition associated cholestasis is caused by the infusate not the route of administration. J Pediatr Surg 1993; 28:391-5.

28. Chan S, . McCowen KC, Thibault A, Keane -Ellison M, Forse RA, Babineau $T$, et al. Incidence, prognosis, and etiology of endstage liver disease in patients receiving home total parenteral nutrition. Surgery 1999; 126:28-34.

29. Simmons MG, Georgeson KE, Figueroa R. Liver failure in parenteral nutrition-dependent children with short bowel syndrome. Transpl Proceed 1996; 28:27I.

30. Meehan JJ, Georgeson KE. Prevention of liver failure in parenteral nutrition-dependent children with short bowel syndrome. J Pediatr Surg 1997; 32:473-5.

31. Nurko S, Aranda JAG, Fishbein E, PerezZuniga MI. Successful use of a chicken-based diet for the treatment of severely malnourished children with persistent diarrhea: $A$ prospective, randomized study. J Pediatr 1997; 131:405-12.

Artigo recebido: 15/04/2003 Aceito para publicação: 16/09/2003 